\title{
Not all narrative shifts function equally
}

\author{
SHANNON SCOTT RICH \\ Texas Woman's University, Denton, Texas \\ and \\ HOLLY A. TAYLOR \\ Tufts University, Medford, Massachusetts
}

\begin{abstract}
Readers of narratives keep track of narrative events and the information associated with these events. Does some of this associated information help structure the processing of and memory for the narrative? In three experiments, we examined the role of basic event building blocks (character, time, and location) in event indexing during text comprehension. These three experiments dealt with perceived coherence, perceived cohesion, and on-line processing, respectively. The results indicated that characters are more likely to serve as event indexes. Although the findings with respect to indexing were similar in all three experiments, interesting differences emerged as a function of the level of text comprehension examined (coherence, cohesion, or on-line processing).
\end{abstract}

Events form a basis for understanding the world. Any one event is defined by its constituent features, which include characters, time, location, event type, and causal associations with other events. Of the possible event features, three (character, time, and location) are considered basic building blocks because they can define single events, rather than relate two or more events together. In the present experiments, we examined the role of these three event features during discourse processing, extending previous research in two ways. First, we directly compared the relative potential of these three event features as indexes. We considered a feature dominant if it showed a greater likelihood of serving as an index than other features did. Second, we examined the role of these features at several levels of discourse processing.

\section{Discourse Comprehension}

Discourse processing occurs on at least three levelsa surface level, a propositional level, and that of a situation model (e.g., Gernsbacher, 1990; Graesser \& Britton, 1996; Kintsch \& van Dijk, 1978; Zwaan \& Radvansky, 1998). While reading, individuals attempt to integrate the exact text into a propositional text base, which they then integrate with their world knowledge to form a situation model (Kintsch \& van Dijk, 1978; Zwaan \& Radvansky, 1998).

Research presented in this manuscript was submitted by the first author in partial fulfillment of the requirements for the master's degree at Tufts University. We gratefully acknowledge Calvin Gidney and Phillip J. Holcomb for discussions about this work. Additional thanks go to Geoffrey Goldschein and Noah Heller for help running the studies and to Kira Grant and Erwin Choi for help coding data. Finally, we appreciate the comments of two reviewers, G. A. Radvansky and R. A. Zwaan, on a previous version of this manuscript. Requests for reprints should be sent to H. A. Taylor, Research Building, 490 Boston Ave., Tufts University, Medford, MA 02155 (e-mail: htaylor@emerald.tufts.edu).
In the present experiments, we examined how event feature continuity affects readers' processing of narratives at the propositional and situation model levels. To do so, we assessed the coherence, cohesion, and on-line integration of event features. Though conceptually similar, cohesion and coherence are distinct phenomena (Giora, 1984; Trabasso, Magliano, \& Langston, 1995; Trabasso, Suh, \& Payton, 1995). Cohesion occurs when readers can connect new information to previously described ideas (Graesser, Millis, \& Zwaan, 1997). Coherence emerges when information show consistent relationships throughout a discourse (Trabasso, Suh, \& Payton, 1995). Both phenomena require integration.

The structure of events has implications for these integration processes. Events have a hierarchical structure, with individual activities combining to form extended events (see, e.g., Neisser, 1986). This hierarchical structure necessitates organization at different levels. Two levels have been suggested: indexing and sequencing (S. J. Anderson \& Conway, 1993; Galambos \& Rips, 1982; Nottenburg \& Shoben, 1980; Taylor \& Tversky, 1997). An index unifies groups of events, often via retrieval tags. A sequencer orders events within a grouping, frequently on the basis of temporal or causal relations. Anomalies at either organization level should impair integration. Since sequencing involves local relationships between events, it relates to cohesion; indexing provides unifying themes and relates to coherence. Although here we focus primarily on indexing, we also address sequencing.

One model of text comprehension, Gernsbacher's structure building framework $(1990,1996)$, addresses the issue of indexing. According to Gernsbacher, individuals build knowledge structures while reading. Knowledge structures group related events on the basis of common features (see also Johnson-Laird, 1983 van Dijk \& Kintsch, 1983; Zwaan \& Radvansky, 1998). Related to the knowledge structures, comprehension involves three 
subprocesses: laying the structure foundation, mapping new information onto the structure, and shifting to a new structure. Once a reader has shifted to a new structure, old structures are less accessible. Our present focus is on the subprocess of shifting to a new structure.

When readers have difficulty integrating new information into their current knowledge structure, they initiate a new one (Gernsbacher, 1990, 1996). Failure to integrate may occur at either a local (sentence) or a global (text) level. Several factors facilitate mapping onto a knowledge structure and consequently promote shifts to new structures when they are absent (Gernsbacher, 1990; Zwaan, Langston, \& Graesser, 1995; Zwaan, Radvansky, Hilliard, \& Curiel, 1998). These factors include referential (having to do with character or theme), temporal, locational, and causal continuity. Although previous findings have suggested a differential impact of these situational continuities on knowledge structure shifts (Zwaan, Langston, \& Graesser, 1995; Zwaan et al., 1998), the relative contribution of each has not been established.

\section{Predictions for Index Dominance}

Three lines of research (discourse processing, autobiographical memory, and use of mental models) make predictions about the role of basic event features as indexes. Although our research relates specifically to narrative comprehension, findings from these three domains converge and warrant further discussion. Because a primary assumption of situation model theory is that individuals represent events that occur in a common spatiotemporal framework, the potential of time and location as dominant indexes will be discussed first, followed by arguments supporting character indexes.

Time as the dominant index. Some autobiographical memory research suggests that feature uniqueness determines index effectiveness (Burt, Mitchell, \& Cowan, 1995). Time proves to be an exception to this theory. By a strict uniqueness theory time should be the most effective, because it changes constantly. In fact, individuals have poor memory for exact time (e.g., Conway \& Bekerian, 1987; Friedman \& Wilkins, 1985; Huttenlocher, Hedges, \& Prohaska, 1988; Larsen, 1993; Linton, 1975; Loftus \& Marburger, 1983; Thompson, Skowronski, Larsen, \& Betz, 1996; Wagenaar, 1986), remembering it instead in a relative fashion (Larsen, 1993; Linton, 1975; Thompson et al., 1996).

There is ample evidence that individuals remember relative temporal information about events. Linton (1975) found that individuals ordered news headlines faster than they dated them. S. J. Anderson and Conway (1993) found that people retrieved more memories in forward chronological order than in other orders (e.g., reverse, free, or order of salience). Thompson, Skowronski, and Betz (1993) have suggested that people use partial temporal information in dating personal events. This partial information includes the accessibility of the event in memory, details of the event itself, world knowledge, temporal re- lationships, and temporal details or tags. Better memory for relative time suggests that time sequences events.

Time may prove a more effective index when smaller time frames are considered. Autobiographical time frames are generally quite expansive; discourse generally involves smaller time frames. Zwaan (1996) showed that temporal shifts in narratives influence comprehension. Similarly, Radvansky, Zwaan, Federico, and Franklin (1998) found evidence that single time frames organize situation models. In these studies, however, time was examined as an isolated variable. When considering multidimensional contributions, Zwaan et al. (1998) found that in two of their three studies time explained reading time variance better than did either location or character. Taylor and Scott Rich (1995) showed that time played a significant role in sequencing events in narrative production. Although time clearly defines events, its role as a sequencer or index remains unclear.

Location as the dominant index. A preponderance of evidence supports location as the dominant index. Excluding time, feature uniqueness predicts that location should be the dominant index (Burt et al., 1995). Locations are more unique than characters, because fewer event types generally occur in a single location than are undertaken by a single person. Several autobiographical studies support this prediction (Burt, 1992; Burt et al., 1995; Wagenaar, 1986). Barsalou (1988) found that although character, time, and location all cued autobiographical events, location cues provided faster access and led to a greater number of events generated per cue.

Mental models research suggests that individuals form unitary representations for single locations, but multiple representations for multiple locations (Franklin \& Tversky, 1990; Franklin, Tversky, \& Coon, 1992; Morrow, Bower, \& Greenspan, 1989; Morrow, Greenspan, \& Bower, 1987; O'Brien \& Albrecht, 1992; Radvansky, Spieler, \& Zacks, 1993; Radvansky \& Zacks, 1991; Wilson, Rinck, McNamara, Bower, \& Morrow, 1993). Using a fan effect paradigm, Radvansky and colleagues (Radvansky et al., 1993; Radvansky \& Zacks, 1991) found increased response time for one object associated with several locations, but no increase for multiple objects in a single location. Similarly Franklin et al. (1992) have suggested that individuals form a single mental model of two characters in one location, but form two models when two characters appear in disparate locations (see also de Vega, 1994).

Character as the dominant index. Although the character feature has largely been ignored as a possible index, the fact that characters are concrete, vivid, and perceived as causal agents supports their potential as a dominant index. In autobiographical memory, Barsalou (1988) found that participants generated more character-based cues than other cue types. Discourse processing research has shown memory organization centered on characters. Morrow et al. (1987) found that time to access information about objects and locations in a scene depended on the dis- 
tance from the narrative protagonist. Zwaan, Langston, and Graesser (1995) found that after a text had been read twice, characters accounted for the most variance in memory. Characters can also play a central role in mental models. Radvansky et al. (1993) found a fan effect reduction when the same character was described in multiple locations, if those locations could not easily accommodate more than one person.

Situational contributions to index dominance. The few studies considering the multidimensionality of event memory show the importance of all three basic event features. Characters, locations, and times all cue autobiographical memory effectively (Barsalou, 1988). In discourse processing, character, time, and location shifts cue new episodes (Zwaan, Langston, \& Graesser, 1995; Zwaan, Magliano, \& Graesser, 1995; Zwaan et al., 1998).

If all three features influence event memory, situational factors could determine which feature may serve as the dominant index. These situational factors could arise from the texts or from reader's goals or prior knowledge. In terms of the reader's goals and knowledge, Zwaan et al. (1998) showed that the importance of location fluctuated, depending on prior knowledge of the narrative space. As such, there may be no a priori expectation for one feature to be dominant. Equating the salience of the features to a large extent, Taylor and Tversky (1997) found that character and location served equally well as memory indexes, followed by time. Taylor and Scott Rich (1995) found similar results for discourse production. Manipulating dimensional salience could change the relative impact of these features. Thus, in the present studies we controlled for dimensional salience to the extent that was possible.

\section{The Present Study}

In the previous discussion, we have outlined the support for each basic event feature as an index. Although there has been empirical support for each feature's being a means of structuring situation representations, the weight of this support falls in favor of location as the primary index (see Zwaan \& van Oostendorp, 1993, for a contrasting view). In our experiments, participants read experiment-generated narratives or "textoids" (Graesser et al., 1997). Shift narratives contained two shifts, pairwise combinations of character, location, and time shifts. The narratives included two different types of shifts to bring them more in line with "real" stories that generally contain multiple shifts. Standard narratives did not contain these shift types.

In the experiments, we examined three aspects of comprehension: coherence in Experiment 1, cohesion in Experiment 2, and on-line integration in Experiment 3. Both coherence and cohesion involve assessing text information after some integration has occurred. For coherence, integration is at a narrative level; for cohesion, it is at a sentence level. Character, locational, and temporal continuity may have different effects, depending on whether integration is global or local. More specifically, shifts in event components serving as indexes should lead to new knowledge structures, and the number of different knowledge structures created should affect coherence. Whether or not a shift prompts a new knowledge structure should affect cohesion. Finally, these continuities may serve different roles during versus after integration. Although coherence and cohesion involve integration, they are measured after integration has taken place.

\section{EXPERIMENT 1 Coherence}

In Experiment 1, participants read narratives one sentence at a time and provided coherence ratings after having completed each narrative. Although character, location, and time all influence comprehension, if the evidence favoring location as a dominant index was supported, location shifts should be most detrimental to coherence.

\section{Method}

Participants. One hundred four undergraduates from Tufts University participated in partial fulfillment of a course requirement. All were native English speakers.

Narratives. Twenty-eight narratives, each 13-14 sentences long (436-610 syllables), were constructed. Twenty-four narratives served as experimental materials (shift narratives), each containing two shifts. The remaining 4 narratives contained no narrative shifts (standard narratives) and served as controls. Each narrative consisted of three approximately equally long sections related by a common theme, but describing different theme-rejated activities. For example, one narrative described preparing for a baby's arrival and included the activities of painting the nursery, setting up the crib, and organizing supplies. Because goal successes, failures, and action completion influence comprehension, the narrative sections included equal numbers of goal successes and failures.

Each shift narrative contained two different shifts. All shifts took place within a single sentence. Shift types included character, location, and time shifts. When one narrative feature shifted, the others remained constant. Shift sentences had a standard formats and length (32-41 syllables). Pairwise combinations of the three shift types resulted in six types of shift narratives.

The character shifts introduced a new character by proper name and made no reference to a previous character. To prevent pronoun confusion, the new character was of the opposite gender. Proper names occurred only in the opening sentence of the narrative and in shift sentences; all other references to characters involved pronouns. Each character shift began with a phrase such as meanwhile to indicate no change in time and repeated the location to verify the absence of a location change.

The location shifts moved the narrative action from one location to another. This shift type presented a problem, because time changes are inherent in location changes (unless you're on Star Trek). Although it was not possible to circumvent this problem completely, the location shifts involved immediately successive times. It has been found that time shifts falling within a scenario boundary do not increase processing time (Zwaan, 1996). The location shifts began with a phrase introducing the new location, such as At the laundro$m a t$, and repeated the character name. The fact that the times were immediately successive was implied through the context.

The time shifts jumped the narrative time forward, to a time ranging from the next day to the following weekend. All time shifts exceeded the duration required for a single activity, thus signaling a new scenario (A. Anderson, Garrod, \& Sanford, 1983; Zwaan, 1996). 
Table 1

Examples of Critical Sentences From Narratives

\begin{tabular}{|c|c|c|}
\hline Sentence Type & $\begin{array}{l}\text { Information in Story } \\
\text { Prior to Shift }\end{array}$ & Shift Sentence \\
\hline Location shift & Jack, beach, afternoon & $\begin{array}{l}\text { At his house, Jack } \\
\text { immediately began the } \\
\text { search through his room } \\
\text { for the misplaced boxes, } \\
\text { hoping he could find them } \\
\text { before the shells were } \\
\text { damaged by the air. }\end{array}$ \\
\hline Character shift & Monica, craft fair, morning & $\begin{array}{l}\text { Meanwhile, Walter browsed } \\
\text { through the booths at the } \\
\text { craft fair looking for } \\
\text { decorations for his apartment } \\
\text { and some gifts for his } \\
\text { numerous nieces and } \\
\text { nephews. }\end{array}$ \\
\hline Time shift & Natalie, carnival, evening & $\begin{array}{l}\text { A week later, Natalie was at } \\
\text { the carnival wearing a t-shirt, } \\
\text { jeans, and a grin on her face, } \\
\text { ready to ride the scariest } \\
\text { rides and play the games. }\end{array}$ \\
\hline Standard & Debbie, ostrich pen, morning & $\begin{array}{l}\text { Debbie began the process } \\
\text { of cleaning the pen, by } \\
\text { grabbing the rake and } \\
\text { raking up the old leaves } \\
\text { and droppings as well as } \\
\text { any soggy food. }\end{array}$ \\
\hline
\end{tabular}

Note-Shift features are underlined.

Such sentences began phrases such as The next morning and included explicit references to the character and location.

The shift narratives followed a basic format. The opening sentence introduced the theme, character, location, and time. The following two sentences elaborated on the first theme-related activity. The fourth sentence provided a possible closure to the first section, without indicating whether a shift would occur. The fifth sentence shifted character, location, or time and introduced a new themerelated activity (see Table 1 for sample shift sentences). The sixth through ninth sentences made up the second section, mirroring the structure of the first. The tenth sentence provided the second shift. The remaining sentences made up the third section and concluded the narrative.

The standard narratives followed this basic structure but did not contain shifts. The fifth and tenth sentences included theme-related activity changes but maintained the same character, location, and time.'

Comprehension questions. Half of the narratives had three accompanying multiple-choice questions with four alternative responses. Questions addressed narrative details. Because the purpose of the comprehension questions was only to promote the processing of narrative content, they were not necessary for all narratives.

Procedure. The participants worked individually. All stimuli were presented on Apple PowerPCs with Superlab software. For the sake of time, the complete set of 28 narratives was divided into two equal subsets. The participants were randomly assigned to a narrative set, and the narratives within each set were randomized. The narratives appeared one sentence at a time, and the participants proceeded through the narratives by pressing a designated key. After each narrative, the participants rated its coherence on a 7-point scale ranging from $1=$ not at all coherent to $7=$ completely coherent . The experimenter defined coherence as "how well integrated the narra- tive is overall." The participants then responded to comprehension questions, if relevant, and proceeded to the next narrative.

\section{Results}

As expected, performance did not differ between the two sets of narratives, so all analyses collapse across this variable. The participants showed $93.5 \%$ accuracy on comprehension questions, indicating that they processed narrative content.

We first assessed whether coherence differed between shift and standard narratives. A repeated measures analysis with the within-subjects factor of narrative type revealed a main effect $\left[F(1,103)=93.07, M S_{\mathrm{e}}=0.43, p<\right.$ $.001]$ : Participants rated standard narratives $(M=6.14)$ as more coherent than shift narratives $(M=5.26)$. Followup analyses determined that all types of shift narratives differed from standard narratives.

Because our main research question addressed different shift types, further analyses included only shift narratives and examined within-subjects factors of shift combination and order. This analysis revealed a main effect of shift combination $\left[F(2,206)=72.32, M S_{\mathrm{e}}=0.38, p<.001\right]$ Narratives with location and time shifts $(M=5.84)$ had the highest ratings, followed by those with character and time shifts $(M=5.09)$ and finally those with character and location shifts $(M=4.85)$. Post hoc analyses showed that all shift combinations differed significantly. No effect of shift order or interaction with order was significant. 


\section{Discussion}

As previous work has shown, any narrative shift decreases perceived coherence (Zwaan, Magliano, \& Graesser, 1995; Zwaan et al., 1998). Here too, participants perceived shift narratives to be less coherent. The relative impact of shifts differed, however. Indexes group events that are related, so knowledge structures should be organized around indexes. Thus event features that group events should have a greater impact on perceived coherence than should features that sequence events. Character and locational continuity affected perceived coherence more than did temporal continuity.

In part, our interpretation of the coherence results may be seen as problematic, given the nature of the stimuli and the task. Each narrative contained two shifts, but participants provided a single rating. Thus, the coherence ratings did not reflect the pure effects of a narrative shift. We believe that our interpretation is justified, however. Even in combination, the presence of a character shift lowered coherence ratings. The narratives receiving the highest coherence ratings did not contain a character shift.

Although more of the previous work suggested that location serves as a dominant index, our results showed that character played a more prominent role. The prediction favoring location may have been made partially in the absence of data about the role of character. More specifically, since character has not generally been discussed as a separate index, it has not been sufficiently evaluated in context with location. In a direct comparison of character and location, Taylor and Tversky (1997) found that character and location played approximately equal roles as indexes. Furthermore, Radvansky et al. (1993) found that using characters as the sentence subject attenuated the location organization. Other evidence argues directly against location as a dominant index. Zwaan and van Oostendorp (1993) found little evidence that readers incorporated spatial aspects of narratives into their situation models. Others have shown similar results (Wilson et al., 1993; Zwaan, Magliano, \& Graesser, 1995; Zwaan et al., 1998).

The results of Experiment 1 differed somewhat from those of the few other multidimensional comparisons of event features. Notably, Taylor and Tversky (1997) and Taylor and Scott Rich (1995) found approximately equal roles for character and location as indexes. The present results favored character over location. Differences in methodology could explain the heightened role of character. First, narrative shifts were not examined in these previous studies. Second, the structure of the events differed. In both Taylor and Tversky (1997) and Taylor and Scott Rich (1995), participants worked with a set of events defined by different instances of two event features. For example, each of four characters took part in an event at each of four locations. Given this structure, character and location seem to organize events equally well. In the present experiment, readers tracked a single character in a single location at a single time. If one does not have to track multiple instances of an event feature (e.g., four different characters or locations), the character dimension might carry more weight.

\section{EXPERIMENT 2 \\ Cohesion}

Experiment 1 showed that character had the greatest impact on coherence ratings, followed by location and finally time. In Experiment 2, we examined the impact of these event features on text cohesion. Cohesion should rely on both indexing and sequencing. Consequently, we predicted that character would greatly affect cohesion ratings and that time would play a more substantial role than it did for coherence.

\section{Method}

Participants. Seventy-two undergraduates from Tufts University participated in partial fulfillment of a course requirement. All participants were native English speakers.

Materials and Procedure. The narratives used in Experiment 1 were again used here. The procedure followed that in Experiment 1, with two exceptions: The participants used a different rating system, and comprehension questions were not used. The participants rated narratives for cohesion after each sentence on a 7-point scale ranging from $1=$ does not fit at all to $7=$ fits very well. The experimenter defined cohesion as "how well the sentence fits with the previous sentence." The comprehension questions were dropped from the procedure because the requirement to assess cohesion after each sentence assured attention to narrative content.

\section{Results}

Some participants used the wrong keys during parts of the experiment but completed the majority of the study as directed. These errors were classified as missing data and led to slightly different degrees of freedom across analyses.

To determine the effects of shifts on perceived cohesion, we compared shift sentence ratings with ratings of corresponding sentences in standard narratives. Analyses showed a main effect of sentence type $[F(1,68)=111.97$, $\left.M S_{\mathrm{e}}=0.57, p<.001\right]$. Participants rated shift sentences $(M=4.10)$ as less cohesive than standard sentences $(M=$ 5.47). Post hoc analyses showed that all shift sentences differed significantly from standard sentences.

Because cohesion ratings occurred after each sentence, the effects of shift types could be examined irrespective of shift order or shift combination. A repeated measures analysis with shift type as the within-subjects factor was used to compare all shift sentences. A main effect of shift type was found $\left[F(2,138)=18.61, M S_{\mathrm{e}}=0.80, p<\right.$ $.001]$. Character shifts $(M=3.75)$ received significantly lower ratings than did both time shifts $(M=4.25)$ and location shifts $(M=4.37)$, which did not differ.

For comparison of the role of time in perceived cohesion with its role in perceived coherence, we conducted an analysis using the mean cohesion rating for the two shift sentences in a narrative. Repeated measures analyses showed a main effect of shift combination $[F(2,138)=$ $\left.38.64, M S_{\mathrm{e}}=0.26, p<.001\right]$. Narratives with location and time shifts $(M=4.54)$ had the highest ratings, followed by those with location and character shifts $(M=$ 
Table 2

Shift Type Effects on On-Line Comprehension Measures: Experiment 3

\begin{tabular}{lccc}
\hline & \multicolumn{3}{c}{ Measure } \\
\cline { 2 - 4 } Shift Type & $\begin{array}{c}\text { Probe } \\
\text { Accuracy }(\%)\end{array}$ & $\begin{array}{c}\text { Probe RT } \\
\text { (msec/syllable) }\end{array}$ & $\begin{array}{c}\text { Reading Time } \\
\text { (msec/syllable) }\end{array}$ \\
\hline Character & 86 & 459 & 528 \\
Location & 82 & 427 & 514 \\
Time & 80 & 410 & 469 \\
\hline
\end{tabular}

4.04) and then those with character and time shifts $(M=$ 3.79). Post hoc analyses showed that all shift combinations differed significantly from one another.

Finally, we examined the extent to which character shifts affected processing. The strong role of character in both coherence and cohesion ratings suggested that character shifts might affect processing beyond the point of the shift itself. This post hoc analysis involved a comparison of time and location shifts following a character shift with those not following a character shift. The results indicated that when time and location shifts followed a character $\operatorname{shift}(M=4.0)$, they received lower ratings than when they did not $(M=4.8)\left[F(1,71)=33.60, M S_{\mathrm{e}}=\right.$ $0.69, p<.001]$.

\section{Discussion}

Experiment 2 extended the findings of Experiment 1 to the issue of narrative cohesion. Shift sentences received lower cohesion ratings than did standard sentences. As in Experiment 1, character shifts influenced the ratings to the greatest extent, both directly and indirectly. Character shifts led to the lowest cohesion ratings. In addition, early character shifts affected ratings of later narrative shifts.

Given the local nature of cohesion, we also predicted that time would play a greater role that it did in ratings of coherence. This prediction was also borne out. In opposition to the results found for coherence, time shifts led to consistently lower ratings than did location shifts. In addition, narratives with both character and time shifts received lower cohesion ratings than did narratives with character and location shifts.

\section{EXPERIMENT 3 On-Line Integration}

Experiments 1 and 2 showed the strong influence that character has on the determination of cohesion and coherence. Both cohesion and coherence ratings are made after integration of narrative events has occurred. It is possible that narrative shifts affect comprehension after integration differently than during integration. Discourse processing occurs through a cyclical process of integration (Kintsch \& van Dijk, 1978; van Dijk \& Kintsch, 1983). During integration, readers attempt to reconcile narrative shifts with their propositional textbase or situation model. After integration has occurred, readers may have successfully reconciled the shifted information. To address this issue, in Experiment 3 we examined on-line comprehension measures.

\section{Method}

Participants. Thirty-five undergraduates from Tufts University participated in partial fulfillment of a course requirement. All were native English speakers. Seven participants' data were not included in analyses; 2 did not complete the experiment, 4 showed chance performance, and 1 was dropped because of experimenter error.

\section{Materials}

Narratives and comprehension questions. The narratives were the same as those used in Experiments 1 and 2. Two additional standard narratives were created for practice. Comprehension questions were again used.

Probes. Each narrative had six associated recognition probes. All probes were three-word phrases describing a specific activity that either occurred in the narrative or was thematically possible, but not in the narrative. Probes fell into three types: across section, within section, and false. Both across- and within-section probes involved an event occurring two to four sentences earlier. Acrosssection probes involved an event in the earlier section-that is, prior to a shift sentence or a corresponding sentence in a standard narrative. Within-section probes involved an event in the same section. False probes named an event that did not occur in the narrative, but that fit the narrative theme. For example, a true probe for the story "Natalie Goes to the Carnival" was decided on games and a false probe was bought ride tickets.

To limit disruption during narrative processing, probes were combined into sets, each containing three probes. Each narrative contained two probe sets, an across set and a within set. The across set included two across-section probes and one false probe. The within set included one within-section probe and two false probes. Thus, each narrative contained an equal number of true and false probes. The greater number of across-section probes provided more power for comparison of shift types. Probe sets were counterbalanced across narratives; half of the narratives had an across set first and half had a within set first

Procedure. The procedure followed that in Experiments 1 and 2, except as noted. As the participants proceeded through a narrative, their sentence reading times were recorded. Each narrative was interrupted twice with a probe task. The probes appeared at the center of the screen in boldface. When the probes appeared, the participants responded "yes" if the event had occurred in the narrative or "no" if it had not, by pressing designated keys.

Before the experiment began, the participants read two standard narratives to acquaint them with the procedure. After practicing, the participants read all 28 narratives, with a 10 -min break after the first half.

\section{Results}

Because the narrative sentences and probes differed in length, reading times and probe reaction times (RTs) were normalized using syllables. Means for these measures will be reported in milliseconds per syllable. RT analyses included only correct responses. As in Experiment 1 , comprehension question responses $(M=91.3 \%$ accuracy) indicated good attention to narrative content. See Table 2 for a summary of the results of Experiment 3.

Probe Responses. ${ }^{2}$ Responses to probes in shift narrative and standard narratives did not differ in accuracy (shift narrative $M=84 \%$; standard narrative $M=86 \%$ ). In contrast, RTs to probes in the two narrative types did 
Table 3

Reading Times Based on Narrative Type: Experiment 3

\begin{tabular}{lc} 
Narrative Type & Reading Time per Sentence (msec) \\
Shift Narratives & \\
Character/location & 9,081 \\
Location/character & 9,852 \\
Character/time & 9,528 \\
Time/character & 9,169 \\
Location/time & 8,759 \\
Time location & 8,620 \\
Standard Narratives & 9,456 \\
\hline
\end{tabular}

differ $\left[F(1,27)=45.51, M S_{\mathrm{e}}=1,069, p<.001\right]$. Participants responded faster to probes in shift narratives $(M=$ $412 \mathrm{msec} / \mathrm{syllable}$ ) than to those in standard narratives $(M=470)$.

The remaining analyses focused on shift narrativesthe primary issue of interest. The experimental design included two probe set types, across and within. Participants responded more quickly and more accurately to withinprobe sets $(M=89 \%$ accuracy and $389 \mathrm{msec} / \mathrm{syllable})$ than to across-probe sets $(M=83 \%$ and 432$)[F(1,27)=$ $36.51, M S_{\mathrm{e}}=0.1, p<.001$ for accuracy, and $F(1,27)=$ $35.24, M S_{\mathrm{e}}=743$ for RT, $\left.p<.001\right]$.

An examination of across-probe sets revealed information about the effect of narrative shifts. The analysis showed main effects of shift type for both accuracy $\left[F(2,54)=4.34, M S_{\mathrm{e}}=1.0, p<.05\right]$ and RT $[F(2,54)=$ $\left.5.78, M S_{\mathrm{e}}=2,995, p<.005\right]$. For accuracy, participants responded more accurately following character shifts $(M=86 \%)$, than following either location shifts $(M=$ $82 \%)$ or time shifts $(M=80 \%)$, which did not differ. In contrast, the RT results showed significantly slower responses following character shifts ( $M=459 \mathrm{msec} /$ syllable) than following either location shifts $(M=427)$ or time shifts $(M=410)$, which did not differ.

As with Experiment 2, we examined the extent of influence of character shifts by analyzing second shifts, both location and time, which either followed a character shift or did not. Both accuracy $\left[F(1,27)=4.74, M S_{e}=0.01\right.$, $p<.05]$ and RT $\left[F(1,27)=8.27, M S_{\mathrm{e}}=4,757, p<.01\right]$ showed significant effects. Participants responded faster and more accurately to second shift probes when the first shift had been a character shift $(M=85 \%$ and 408$)$ than when it had not $(M=79 \%$ and 461$)$.

Reading times. Analyses of average narrative reading time showed no effect of narrative type, whether shift or standard. Further examination showed that when narratives were broken down into seven types, including the shift narrative combinations and the standard narratives, a main effect of narrative type emerged $[F(6,162)=11.17$, $\left.M S_{\mathrm{e}}=481,951, p<.001\right]$. Of all the narrative types, reading times for standard narratives fell in the middle (see Table 3). Further analyses showed that reading time differences between the seven narrative types resulted from the shift sentences and corresponding sentences in standard narratives, not from other narrative sentences. Fur- ther analyses of shift sentences showed a main effect $\left[F(2,54)=7.37, M S_{\mathrm{e}}=3,529, p<.001\right]$. Participants took equal amounts of time to read character $(M=528)$ and location shifts $(M=514)$, but significantly less time to read time shifts $(M=469)$.

\section{Discussion}

As in Experiments 1 and 2, event features differentially affected processing, in this case on-line processing. All three on-line measures (reading time, probe accuracy, and probe RT) showed differential effects. For reading time, participants read time shifts the fastest. Both character and location shifts required more reading time, but they did not differ from one another. In terms of probe responses, accuracy and RT measures did not completely converge. Probe responses were most accurate after character shifts and least accurate after time shifts. In contrast, the longest RTs appeared after character shifts. RTs to location and time shifts were faster and did not differ.

At first glance, the probe response findings could indicate a speed-accuracy tradeoff. We do not believe that this is the case since any tradeoff was evident only for a select portion of the data. Only responses following character shifts showed this pattern. Responses following location and time shifts showed converging evidence.

Instead, we propose that our three on-line measures may tap different processes, all showing the strong role of character in event indexing. Reading time reflects processing during integration. The long reading times after character shifts indicate a significant interruption in integration. In contrast, probe RTs reflect accessibility of information in previously constructed knowledge structures. RTs after character shifts were slowest, suggesting that information from the previous structure was less accessible. Finally, probe accuracy illustrates the associative strength between events indexed by a common feature. Participants were most accurate after character shifts. In this case, events in the old knowledge structure would be indexed by the previously described character and highly associated with this character.

Although it was not our primary focus, we found evidence that readers tracked activity shifts. Unexpectedly, participants responded more slowly to probes in standard narratives than to those in shift narratives. Activity shifts, a control variable in standard narratives, can explain this finding. Activity shifts changed the specific theme-related action. For example, within the theme of preparing for the baby an activity shift might involve going from painting the nursery to setting up the crib. In shift narratives, the character, location, and time shifts explained the activity shifts. Standard narratives did not have this explanatory mechanism.

\section{GENERAL DISCUSSION}

In three experiments, we examined the effects of the basic building blocks of events (character, location, and time) on the processing of narrative events. In Experi- 
ment 1 , we assessed the effects of narrative continuities on coherence ratings. In Experiment 2, we examined cohesion and in Experiment 3 we used on-line comprehension measures. All three experiments supported character as the dominant event index.

Previous research has illustrated the importance of thinking about event memory as multidimensional (Zwaan, Magliano, \& Graesser, 1995; Zwaan et al., 1998). The multidimensional components of events have been compared in only a few studies, however (see Gernsbacher, 1990, 1996; Zwaan, Magliano, \& Graesser, 1995; Zwaan et al., 1998). Within a multidimensional framework, some attempts of direct comparison have been made. Taylor and Tversky (1997), comparing pairs of these features, found that both character and location served as better indexes than did time. Taylor and Scott Rich (1995) found similar results in text production. In the present study, we directly compared all three components and found that character shifts were most disruptive to narrative processing. This finding held for assessments of narrative coherence, cohesion, and on-line processing.

Although characters are a central narrative feature, the character component has been largely ignored in empirical studies, perhaps because its central role is assumed. This assumption, however, has not been thoroughly investigated. Gernsbacher (1990) and A. Anderson et al. (1983) discuss character shifts within the context of episode shifts. But, episode shifts do not show a pure effect of character; episode shifts generally include multiple simultaneous shifts (character, location, and time).

Our explicit examination of character showed that it had a broad influence. Character shifts influenced processing both at the shift itself and later in the narrative. In Experiment 1, character shifts disrupted coherence more than location and time shifts did. This is consistent with Trabasso, Magliano, and Langston's (1995) finding that character, theme, and goal continuities influenced coherence. In Experiment 2, character shifts were also most disruptive to cohesion ratings. This contrasts with Trabasso, Magliano, and Langston's (1995) finding that at a local level readers monitor situational features, such as spatial, temporal, and causal continuities.

In Experiment 3, we used on-line measures to examine the effects of these event features during integration. As in Experiments 1 and 2, reading time and probe RT showed that character shifts disrupted integration to a greater extent than did other shift types. In contrast, the probe accuracy results suggested that character indexes provide a strong associative link for events within a knowledge structure. Participants responded most accurately to probes following character shifts. A character shift precipitated a switch to a new knowledge structure, making previously described events less accessible (Gernsbacher, 1990). At the same time, events within the old structure were strongly associated with the character index.

Location came in a close second for its indexing power. For coherence, location shifts fell between character and time shifts. With the more local nature of cohesion, lo- cation shifts showed slightly less disruption than did time shifts. Character shifts still showed the greatest disruption. As discussed earlier, on-line measures seemed sensitive to different processes, including integration, accessibility, and event indexing. Integration times for character and location shifts were equivalent, but information was more accessible after a location shift than after a character shift. Finally, location shifts did not seem to unite events to the same degree as character shifts. These finding fall in line with Radvansky et al.'s (1993) comparison of location and character organizations of situation models. While they found substantial evidence for a location index, they also showed that using characters as sentence subjects or using locations unlikely to accommodate more than one person (e.g., phone booth) reduced the location-based organization.

Time was the final event component that we examined. In event organization, time sequences events (Taylor \& Scott Rich, 1995). Thus, time shifts should be more disruptive at a local level. Our results support this contention. Overall, time affected processing the least but played a greater role in cohesion. This supports Trabasso, Magliano, and Langston's (1995) conclusion that readers monitor local continuities when considering cohesion. Time may have played a lessened role because it was defined relatively rather than by means of absolute temporal markers. However, even studies done with absolute time markers have shown that time does not play a prominent role (e.g., Conway \& Bekerian, 1987; Friedman \& Wilkins, 1985; Huttenlocher et al., 1988; Larsen, 1993; Linton, 1975; Loftus \& Marburger, 1983; Thompson et al., 1996; Wagenaar, 1986). Also, individuals seem to prefer to organize time relatively.

The finding that event features play differential roles in comprehension is not inconsistent with the multidimensional framework of the event-indexing model (Zwaan, Langston, \& Graesser, 1995; Zwaan et al., 1998). In our experiments, all shift types disrupted processing. Narrative shifts resulted in lower coherence and cohesion ratings than did standard narratives. This finding supports and refines the multidimensional nature of situation models presented by Zwaan and Radvansky (1998). Their model suggests that readers track at least five dimensions: time, space, causation, intentionality, and protagonist. Our findings support the proposal that readers update protagonist, space, and time in their mental representations. Furthermore, we suggest that although all features are tracked, they structure event memory differentially.

Although our results consistently showed the dominant role of character at multiple levels of discourse processing, we do not propose that the dominance ordering found here might be universal. To the extent that was possible, we equated the salience of the three event features. Narrative activities did not occur in unusual locations or at unusual times, or involve unusual characters. The relative salience of these dimensions, however, could be manipulated in a narrative. A murder mystery, for example, might focus more on the characters involved, whereas a histor- 
ical piece might focus on a particular location or time periods. Therefore, situational contributions to the salience of these dimensions cannot be ignored. Other situational variables, such as whether participants studied a map (Zwaan et al., 1998), whether locations can accommodate multiple characters (Radvansky et al., 1993), and whether participants could read a narrative multiple times (Zwaan, Langston, \& Graesser, 1995) have already been shown to affect situation model construction. Models such as the event-indexing model (Zwaan \& Radvansky, 1998) are correct to incorporate flexibility in the extent to which event dimensions are updated.

Situational contributions not withstanding, our experiments provide a starting point for directly comparing the relative role of event components during narrative comprehension. For our basic case, in which none of the event features (time, location, or character) receive specific attention within the narratives, character serves as the dominant index. Thus, the assumption that characters play a central role in narratives seems justified. This central role is based on the fact that characters are concrete and vivid and are perceived as causal agents of events. For this reason, narratives almost always include characters. Indeed, Taylor and Scott Rich (1995) found that when participants wrote narratives that were based on a specific set of locations and times, they almost always added specific characters. Thus, readers expect characters to be in narratives and they track the progress of those characters.

\section{REFERENCES}

Anderson, A., Garrod, S. C., \& Sanford, A. J. (1983). The accessibility of pronominal antecedents as a function of episode shifts in narrative text. Quarterly Journal of Experimental Psychology, 35A, 427-440.

Anderson, S. J., \& Conway, M. A. (1993). Investigating the structure of autobiographical memories. Journal of Experimental Psychology: Learning, Memory, \& Cognition, 19, 1178-1196.

Barsalou, L. W. (1988). The content and organization of autobiographical memories. In U. Neisser \& E. Winograd (Eds.), Remembering reconsidered: Ecological and traditional approaches to the study of memory (pp. 193-243). Cambridge: Cambridge University Press.

BURT, C. D. B. (1992). Retrieval characteristics of autobiographical memories: Event and date information. Applied Cognitive Psychology, 6, 389-404.

Burt, C. D. B., Mitchell, P. T. F., \& Cowan, T. M. (1995). A snapshot of autobiographical memory retrieval characteristics. Applied Cognitive Psychology, 9, 61-74.

CONWAY, M. A., \& BEKERIAN, D. A. (1987), Organization in autobiographical memory. Memory \& Cognition, 15, 119-132.

DE VEGA, M. (1994). Characters and their perspectives in narratives describing spatial environments. Psychological Research, 56, 116-126.

FrankLIN, N., \& TVERSKY, B. (1990). Searching imagined environments. Journal of Experimental Psychology: General, 119, 63-76.

Franklin, N., TVersky, B., \& CoOn, V. (1992). Switching points of view in spatial mental models. Memory \& Cognition, 20, 507-518.

Friedman, W. J., \& Wilkins, A. J. (1985). Scale effects in memory for the time of events. Memory \& Cognition, 13, 168-175.

Galambos, J. A., \& Rips, L. J. (1982). Memory for routines. Journal of Verbal Learning \& Verbal Behavior, 21, 260-281.
GERNSBACHER, M. A. (1990). Language comprehension as structure building. Hillsdale, NJ: Erlbaum.

GeRnSBACHER, M. A. (1996). The structure-building framework: What it is, what it might also be, and why. In B. K. Britton \& A. C. Graesser (Eds.), Models of understanding text (pp. 289-311). Mahwah, NJ: Erlbaum.

Giora, R. (1984). Notes toward a theory of text coherence. Poetics Today, 6, 699-715.

Graesser, A. C., \& Britton, B. K. (1996). Five metaphors for text understanding. In B. K. Britton \& A. C. Graesser (Eds.), Models of understanding text (pp. 341-351). Mahwah, NJ: Erlbaum.

Graesser, A. C., Millis, K. K., \& ZwaAN, R. A. (1997). Discourse comprehension. Annual Review of Psychology, 48, 163-189.

Huttenlocher, J., Hedges, L., \& Prohaska, V. (1988). Hierarchical organization in ordered domains: Estimating the dates of events. Psychological Review, 95, 471-484.

Johnson-LAird, P. N. (1983). Mental models. Cambridge, MA: Harvard University Press.

KINTSCH, W., \& VAN DiJK, T. A. (1978). Toward a model of text comprehension and production. Psychological Review, 95, 163-182.

LARSEN, S. F. (1993). Representation of time in memory: The dating of events. Paper presented at the Workshop on Memory and Mental Representations, Rome.

LinTON, M. (1975). Memory for real-world events. In D. A. Norman \& D. E. Rumelhart (Eds.), Explorations in cognition (pp. 376-404). San Francisco: Freeman.

Loftus, E. F., \& Marburger, W. (1983). Since the eruption of Mt. St. Helers, has anyone beaten you up? Improving the accuracy of retrospective reports with landmark events. Memory \& Cognition, 11 , 114-120.

Morrow, D. G., Bower, G. H., \& Greenspan, S. L. (1989). Updating situation models during narrative comprehension. Journal of Memory \& Language, 28, 292-312.

Morrow, D. G., Greenspan, S. L., \& Bower, G. H. (1987). Accessibility and situation models in narrative comprehension. Journal of Memory \& Language, 26, 165-187.

NeISSER, U. (1986). Nested structure in autobiographical memory. In D. C. Rubin (Ed.), Autobiographical memory (pp. 71-81). Cambridge: Cambridge University Press.

Nottenburg, G., \& Shoben, E. J. (1980). Scripts as linear orders. Journal of Experimental Social Psychology, 16, 329-347.

O'Brien, E. J., \& Albrecht, J. E. (1992). Comprehension strategies in the development of a mental model. Journal of Experimental Psychology: Learning, Memory, \& Cognition, 18, 777-784.

Radvansky, G. A., Spieler, D. H., \& Zacks, R. T. (1993). Mental model organization. Journal of Experimental Psychology: Learning, Memory, \& Cognition, 19, 95-114.

RadVANSKY, G. A., \& ZaCKS, R. T. (1991). Mental models and the fan effect. Journal of Experimental Psychology: Learning, Memory, \& Cognition, 17, 940-953.

Radvansky, G. A., Zwaan, R. A., Federico, T., \& Franklin, N. (1998). Retrieval from temporally organized situation models. Journal of Experimental Psychology: Learning, Memory, \& Cognition, 24, 1224-1237.

TAYLOR, H. A., \& SCOTT RICH, S. (1995). Who, where, and when: Use of events in narrative production. Paper presented at the 36 th Annual Meeting of the Psychonomic Society, Los Angeles.

TAYLOR. H. A., \& TVERSKY, B. (1997). Indexing events in memory: Evidence for index dominance. Memory, 5, 509-542.

Thompson, C. P., Skowronski, J. J., \& BETZ, A. L. (1993). The use of partial temporal information in dating personal events. Memory \& Cognition, 21, 352-360.

Thompson, C. P., Skowronski, J. J., Larsen, S. F., \& Betz, A. L. (1996). Autobiographical memory: Rememberin what and remembering when. Mahwah, $\mathrm{NJ}$ : Erlbaum.

Trabasso, T., Magliano, J. P., \& Langston, M. (1995, November). Situational cohesion and coherence in story understanding. Paper presented at the 36th Annual Meeting of the Psychonomic Society, Los Angeles. 
Trabasso, T., SUh, S., \& Payton, P. (1995). Explanatory coherence in understanding and talking about events. In M. A. Gernsbacher \& T. Givon (Eds.), Coherence in spontaneous text (pp. 189-2 I4). Amsterdam: John Benjamins.

VAN Disk, T. A., \& KINTSCH, W. (1983). Strategies of discourse comprehension. New York: Academic Press.

WAGENAAR, W. A. (1986). My memory: A study of autobiographical memory over six years. Cognitive Psychology, 18, 225-252.

Wilson, S. G., Rinck, M., MCNamara, T. P., Bower, G. H., \& MorRow, D. G. (1993). Mental models and narrative comprehension Some qualifications. Journal of Memory \& Language, 32, 141-154.

ZWAan, R. A. (1996). Processing narrative time shifts. Journal of Experimental Psychology: Learning, Memory, \& Cognition, 22, 11961207.

Zwaan, R. A., Langston, M. C., \& Graesser, A. C. (1995). The construction of situation models in narrative comprehension: An eventindexing model. Psychological Science, 6, 292-297.

ZWAan, R. A., Magliano, J. P., \& GRaesser, A. C. (1995). Dimensions of situation model construction in narrative comprehension. Journal of Experimental Psychology: Learning, Memory, \& Cognition, 21, 386-397.

ZwaAn, R. A., \& Radvansky, G. A. (1998). Situation models in language comprehension and memory. Psychological Bulletin, 123 , 162-185.

Zwaan, R. A., Radvansky, G. A., Hilliard, A. E., \& Curiel, J. M. (1998). Constructing multidimensional situation models during reading. Scientific Studies of Reading, 2, 199-220.
ZWAan, R. A., \& VAN OOSTENDORP, H. (1993). Do readers construct spatial representations in naturalistic story comprehension? Discourse Processes, 16, 125-143.

\section{NOTES}

1.Copies of all experimental texts are available on request from the second author.

2. In all analyses, we examined probe sets, including both true and false probes. This analysis is justified in that it equates the number of probes of each type. Also, false probes could be included because they involved theme-consistent events. Because across- and within-probe sets included different numbers of false probes, we conducted separate analyses to rule out true/false differences as an interpretation of our findings. The results for true probes mirrored the findings for true and false probes combined, with one exception. The analysis of RT on true probes also showed an interaction between narrative type and probe type $\left[F(1,27)=42.10, M S_{\mathrm{e}}=5,838.04, p<.001\right]$. Simple effects showed that for standard narratives, responses to within probes $(M=$ $611 \mathrm{msec}$ ) were significantly longer than responses to across probes $(M=464)$. Shift narratives showed the reverse pattern, with responses to within probes $(M=404)$ significantly shorter than responses to across probes $(M=446)$.

(Manuscript received June 30, 1998; revision accepted for publication January 1,2000 .) 